\title{
RADIOCARBON CHRONOLOGY OF EARLY MEDIEVAL ARCHAEOLOGICAL SITES IN NORTHWESTERN RUSSIA
}

\author{
S. G. POPOV, YU. S. SVEZHENTSEV and G. I. ZAITSEVA
}

Institute of Archaeology, St. Petersburg Branch, Russian Academy of Sciences, St. Petersburg 192041 Russia

\begin{abstract}
A reliable archaelogical chronology for medieval sites in northwestern Russia depends in part on a refined regional calibration scale for ${ }^{14} \mathrm{C}$ dates. We present results of dates on tree-ring series from Novgorod that show a systematic discrepancy from European calibration curves, and that underline the need for more extensive ${ }^{14} \mathrm{C}$ dating as the basis of an extended calibration curve for the region.
\end{abstract}

\section{INTRODUCTION}

The main problem in studying early medieval archaeology in northwestern Russia is refining the chronology. Archaeological sites of the first millennium AD consist of banks of earth of the longbarrow and mound cultures and their respective settlements. Over the past 15 years, excavations have contributed little to the chronology of pre-Christian cultures. Occasional finds from diverse structures that cover a wide range of dates make typological association an unreliable dating method. Radiocarbon dating provides a promising tool for the solution of these problems. To establish a detailed chronology of the second half of the first millenium AD of northwestern Russia, we must obtain a representative series of ${ }^{14} \mathrm{C}$ dates for settlements and burials of that time, and integrate these with established chronologies of later city centers. The chronology of prehistorical Novgorod, the principal city of that region, is based on the correlation between the cultural layer levels and dendrochronologically dated pavement levels.

\section{DENDROCHRONOLOGY AND RADIOCARBON DATING OF NORTHWEST RUSSIA}

Bassalygo, Sorokin and Khoroshev (1988) based their research on Novgorod absolute dendrochronology on the pioneering work of Chernykh (1985a, b, 1987), who established a dendroscale for Ryurikovo Gorodische, Pskov, and Ladoga, which extends from the early 15th to the early 7 th centuries. Extension of the absolute dendrochronologically based time scale is hampered by the lack of tree-ring samples from eastern Europe. The West European time scale, based on oak and pine from Northern Ireland and Germany, embraces the interval from the present to ca. 10,000 BC (Schmidt et al. 1988), and is a reliable foundation for archaeological chronologies. For northwestern Russia, however, direct dendrochronological dating of archaeological remains of medieval times suffers from a lack of suitable material (Popov 1989b).

Tree rings are considered universal indicators of ${ }^{14} \mathrm{C}$ concentration in the atmosphere, and thus serve as the basis for the construction of ${ }^{14} \mathrm{C}$ calibration curves. Kocharov et al. (1985) have studied astrophysical phenomena affecting ${ }^{14} \mathrm{C}$ variation in the atmosphere. High-precision ${ }^{14} \mathrm{C}$ measurements have also been used to correlate floating dendroscales with absolute chronological systems (Bitvinskas et al. 1978; Marsadolov 1985; Markov et al. 1987).

\section{RADIOCARBON CALIBRATION AT NOVGOROD}

Kocharov et al. (1985) and Kolchin et al. (1984) measured ${ }^{14} \mathrm{C}$ concentration in tree rings from $\mathrm{AD}$ 1074-1402 from excavations in ancient Novgorod. To test the applicability of the calibration curves (Stuiver and Pearson 1986; Stuiver and Becker 1986) to the chronology of northwestern 


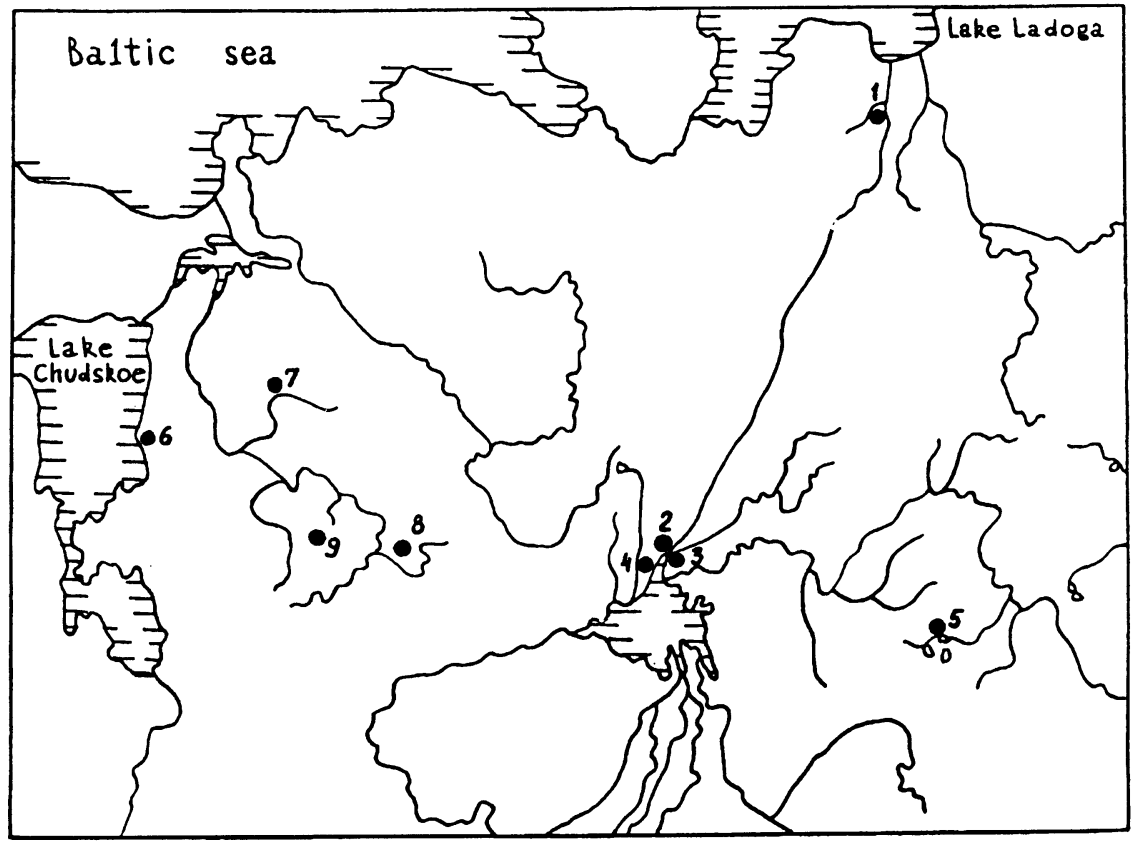

Fig. 1. Dated archaeological sites in the Northwest of Russia: 1 . Staraya Ladoga; 2. Novgorod; 3. Ryurikovo Gorodische; 4. Vasilyevskoe; 5. Zaozerye; 6. Storozhinets; 7. Beryozno; 8. Kotorsk; 9. Skovorodka

TABLE $1 .{ }^{14} \mathrm{C}$ Dates of Tree Rings from Novgorod Excavations

\begin{tabular}{lcrll}
\hline Sample & $\begin{array}{c}\text { Tree-ring } \\
\text { interval } \\
\text { no. }\end{array}$ & $\begin{array}{c}{ }^{14} \text { C age } \\
(\mathrm{AD})\end{array}$ & $\begin{array}{l}\text { Cal AD ages } \\
\text { Stuiver and } \\
\text { Pearson }(1986)^{*}\end{array}$ & $\begin{array}{l}\text { Cal AD ages Stuiver and } \\
\text { Becker }(1986)^{*}\end{array}$ \\
\hline TC-VIII-25-78 & & & & \\
LE-4572 & $882-884$ & $866 \pm 30$ & $928(960) 993$ & $900(910,971) 993$ \\
LE-4573 & 888 & $939 \pm 70$ & $973(1006) 1040$ & $985(1002) 1038$ \\
LE-4574 & $892-895$ & $928 \pm 35$ & $994(1009) 1024$ & $985(1004) 1023$ \\
LE-4576 & $901-902$ & $1051 \pm 70$ & $1027(1124) 1221$ & $1025(1121) 1217$ \\
LE-4580 & $923-924$ & $846 \pm 60$ & $886(943) 1000$ & $885(941) 996$ \\
LE-4581 & $930-935$ & $936 \pm 50$ & $983(1007) 1030$ & $985(1008) 1030$ \\
LE-4582 & $936-937$ & $1031 \pm 80$ & $1018(1118) 1217$ & $1003(1006,1115) 1212$ \\
LE-4583 & $943-950$ & $1043 \pm 70$ & $1024(1118) 1211$ & $1030(1080,1135,1162) 1218$ \\
LE-4586 & $958-962$ & $922 \pm 40$ & $979(1000) 1022$ & $982(1002) 1022$ \\
TC-VIII-25-63 & & & & \\
LE-4589 & $913-916$ & $932 \pm 60$ & $974(1002) 1031$ & $980(1005,1145) 1146$ \\
LE-4591 & $921-922$ & $904 \pm 55$ & $929(976) 1022$ & $980(995) 1020$ \\
LE-4592 & $925-927$ & $861 \pm 40$ & $894(944) 993$ & $898(910,966) 990$ \\
LE-4593 & $930-932$ & $957 \pm 60$ & $992(1018) 1044$ & $1032(1042,1116,1150) 1158$ \\
LE-4594 & $935-937$ & $1028 \pm 30$ & $1034(1099) 1163$ & $1031(1095) 1159$ \\
LE-4595 & $938-940$ & $905 \pm 30$ & $979(998) 1016$ & $995(1007,1025) 1027$ \\
LE-4596 & $942-945$ & $824 \pm 40$ & $882(926) 969$ & $782(785,940) 990$ \\
\hline
\end{tabular}

*Laboratory error multipliers were not available for these calibrations 
Russia (Fig. 1), we dated tree rings from Novgorod in 1987. ${ }^{14} \mathrm{C}$ measurements were made at the Radiocarbon Laboratory, St. Petersburg Branch of the Institute of Archaeology, Russian Academy of Sciences, under the supervision of S. G. Popov. Chemical preparation of the samples was performed by Yu. S. Svezhentsev and G. I. Zaitseva. ${ }^{14} \mathrm{C}$ activity was measured in liquid scintillation counters with 3 - and 7-ml vial capacities. The ${ }^{14} \mathrm{C}$ ages were based on the half-life of ${ }^{14} \mathrm{C}, 5568 \pm 30 \mathrm{yr}$, and the errors $( \pm 16 \mathrm{yr})$ on total measurement time (44-48 h) and the amount of synthesized benzene. We made no corrections for isotopic fractionation. (The authors wish to thank A. F. Ur'eva for providing dendrochronologically dated samples.) Samples were prepared from segments of two structural timbers (TC-VIII-25-63, felled $A D$ 959-960 and TC-VIII-25-78, felled $A D$ 968) from Level 25 of the Troitskii-VIII excavation site. Sixteen samples contained from 1 to 8 rings and represented the period AD 882-962. Table 1 and Figure 2 show the results of these measurements.

It goes without saying that the "unsmoothed" results of dating individual rings cannot be used for calculating the ${ }^{14} \mathrm{C}$ dates of archaeological objects. This is largely because, for any particular object, the ${ }^{14} \mathrm{C}$ activity of samples is measured by many rings (charcoal or wood in a poor state of preservation), and the radiocarbon age determined has already been averaged to some extent. Therefore, in age calculation, another correction often has to be introduced to take into account the life period of the tree, if it can be determined even approximately. Weighted averages of the ${ }^{14} \mathrm{C}$ dates of the two bulk samples (weighted according to the magnitude of their statistical errors) are quite close to the mean calendar ages for the rings comprising the sample (Table 2).

TABLE 2. Averaged Radiocarbon Dates from Novgorod

\begin{tabular}{lcc}
\hline Sample & $\begin{array}{c}\text { Mean calendar ring date } \\
(\mathrm{yr} \mathrm{AD})\end{array}$ & $\begin{array}{c}\text { Averaged }{ }^{14} \mathrm{C} \text { date } \\
(\mathrm{yr} \mathrm{AD})\end{array}$ \\
\hline TC-VIII-25-78 & 926 & $935 \pm 16$ \\
TC-VIII-25-63 & 930 & $919 \pm 15$ \\
Total & 928 & $927 \pm 11$ \\
\hline
\end{tabular}

Curves may differ from each other because of variables stemming from different approaches to: 1) measuring the ${ }^{14} \mathrm{C}$ activity in tree rings; 2) diverse referencing standards; and 3) processing of results. Some investigators use a smoothed curve, which excludes deviations in ${ }^{14} \mathrm{C}$ concentration, whereas others use a "fine" structured curve, which takes into account short-term ${ }^{14} \mathrm{C}$ variations (Dergachyov 1983).

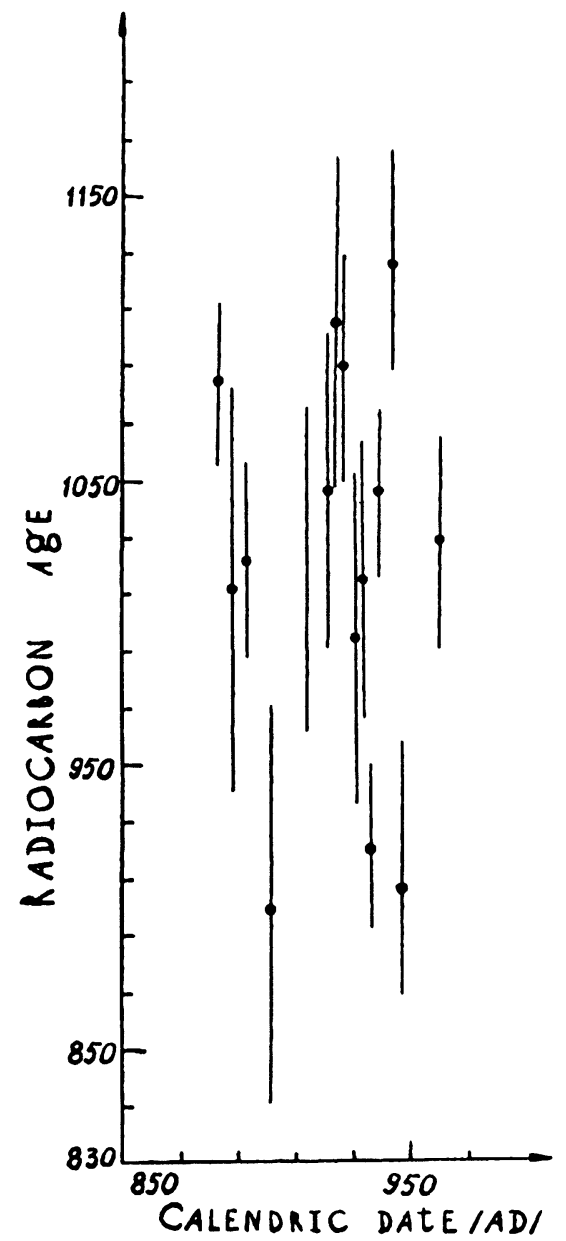

Fig. 2. The results of dating samples from tree rings of wood from Novgorod excavations. 
We averaged ages in a "sliding" window comprising five dates in a calendar sequence and sequentially shifting by one sample. The calibration obtained in a range of dates with an error of $1 \sigma= \pm 20 \mathrm{yr}$ is compared in Figure 3. Shown also in Figure 3 are calibrations for that time range plotted by Stuiver and Pearson (1986) and Stuiver and Becker (1986). The measurements and calculations were carried out at two laboratories using identical methods, obviating the difficulties involved in correlating results from different laboratories and preventing the distortion of curves.

Figure 3 shows that our calibration curve for an 80-yr interval shows variations in ${ }^{14} \mathrm{C}$ concentration in the atmosphere similar to those recorded by other laboratories ( $c f$. particularly curve 3, based on samples of 10 rings). Figure 3 also shows a systematic shift toward younger ages in our data by an average of 80-90 yr compared to curves 1 and 3 , and shows close agreement between ${ }^{14} \mathrm{C}$ and treering dates. This may be attributed to such uncertainties as varying conditions of the trees' growth, regional climatic factors and lack of isotopic fractionation (Arslanov 1978).

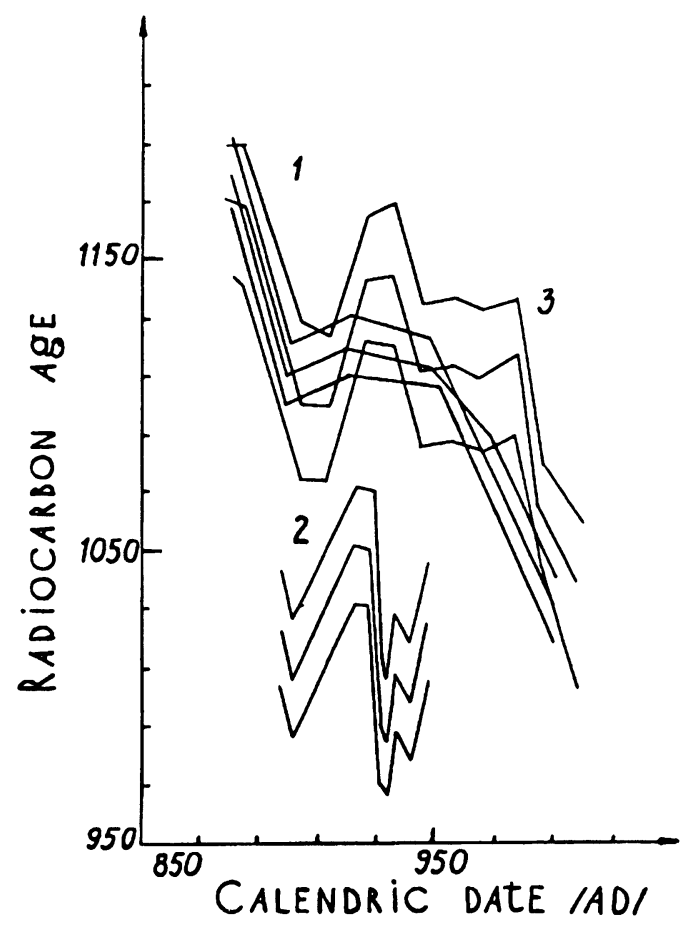

Fig. 3. Calibration curve portions for the late first millennium AD: 1) from data of Stuiver and Becker (1986); 2) from data reported in this paper; 3) from data of Stuiver and Pearson (1986)

The differences in the results outlined above are not very important, and do not rule out the utility of calibration curves for the first millennium AD. However, for the Novgorod project, we prefer to use the portion of our curve that takes into account the regional peculiarities of the ${ }^{14} \mathrm{C}$ variations of the late 9th and early 10th centuries. The time interval, $\mathrm{AD} 0-1000$, is known for its variability in ${ }^{14} \mathrm{C}$ concentration in the atmosphere. Further, the calibration curve trend has an extremum, which increases the discrepancy between the ${ }^{14} \mathrm{C}$ and calendar ages. A series of short-term ${ }^{14} \mathrm{C}$ variations of high amplitude noted in the second half of the first millennium $\mathrm{AD}$ is an added uncertainty. In our results, it is reflected by a difference of as much as $150 \mathrm{yr}$ between the ${ }^{14} \mathrm{C}$ ages of some rings and their calendar ages (LE-4576). In some, cases several calendar dates correspond to one ${ }^{14} \mathrm{C}$ date (cf. Table 1). Thus, a series of dates on one sample would improve the reliability of the calibration.

We ${ }^{14} \mathrm{C}$-dated several structures and excavations into the original ground at the Vasilevskoye I site in the Novgorod area. All archaeological evidence dates this complex to the 9th-10th centuries (Nosov 1990). Table 3 shows the results. Both sites were contemporaneous and belonged to the same construction period.

Table 3 also shows results from other excavations in the Novgorod area. ${ }^{14} \mathrm{C}$ dates of wood from the walkway and of a log cabin frame from the 1987 excavation at Zemlyanoe Gorodische in Staraya Ladoga correspond to dates for the overlying layers of the second half of the 10th century $\mathrm{AD}$. The base of the structure in the upper original ground of the mound near Kotorsk village dates to the early 10th century, whereas charcoal and birch bark from the cremation burial on top of 
Mound 2 near Skovorodka village dates to the late 9 th and early 10 th centuries. These ${ }^{14} \mathrm{C}$ dates agree well with the archaeological dates.

We have dated some "long-barrow" cultural sites. Concurrent with the log dwelling on the Storozhinets hillfort east of Lake Chudskoe (Popov 1985; 1988) were Burials 1 and 2 in the ground pits under Barrow 18 of the Beryozno burial ground (Kuz'min 1988); the dwelling structure on the Zaozerye site was constructed somewhat later (Konetskii 1987). Dates of the upper level of the fortifications of the Storozhinets site (mid-6th century) are confirmed stratigraphically, the base of the log dwelling being embedded in the overlying earth bank (Popov 1989a). All the ${ }^{14} \mathrm{C}$ dates agree well with archaeological dates. We also successfully dated more recent occupations at Ryurikovo Gorodische.

The bases of interconnected structures (presumably, princes' tower chambers) in use from the 12th-15th centuries were dated archaeologically (Nosov 1987). ${ }^{14} \mathrm{C}$ dates, LE-4405 and LE-4411, of timber remnants from Ryurikovo suggest the mid-13th century as the time of the original erection of the structures. The time of their destruction (mid-15th century) was determined by dating the charcoal from the floor that collapsed into the base level.

Dating bone collagen is technically more complicated than dating charcoal. To a great extent, results depend on chemical preparation of the samples, which sometimes fails to remove all contaminating carbon (Arslanov 1987). This is probably why the date on bones (LE-4415, Table 3) is younger, although the use of burned structures as refuse pits cannot be ruled out. The posthole (LE-4415, Table 3) also dates to later times. A single first millennium date for charcoal from the moat at Ryurikovo Gorodische lake (LE-4404, Table 3; Nosov 1987) is not sufficient to guarantee the results.

\section{CONCLUSION}

${ }^{14} \mathrm{C}$ measurements of tree rings from excavations of ancient Novgorod suggest that the average ${ }^{14} \mathrm{C}$ and tree-ring dates for AD 882-962 agree well. However, a consistent discrepancy of 80-90 yr is apparent between Russian and European calibration curves. Recent interlaboratory comparisons both at home and abroad rule out laboratory preparation techniques as a possible cause for this discrepancy, which is more likely due to regional climatic fluctuation as well as isotopic fractionation.

We are in possession of wood that would enable us to construct a continuous calibration curve for the interval, $A D$ 750-1000. To refine the archaeological chronology of northwestern Russia, it would be important to extend this curve to $\mathrm{AD} 400-500$. This would be feasible only if the excavations now in progress at Staraya Ladoga were continued. Until the extended calibration curve has been constructed, the above-mentioned calibrations may be used. At the same time, for settlements of the late first millennium $\mathrm{AD}$ in the Novgorod area, our portion of the calibration curve should be used.

Extensive ${ }^{14} \mathrm{C}$ dating should clarify the chronological picture of northwestern Russia in the second half of the first millenium $\mathrm{AD}$. It would be important to date the appearance of the tumuli, as well as the long-barrow and mound cultures. Another area for future research is the relation between the long-barrow culture and the preceding Early Iron Age. Serial ${ }^{14} \mathrm{C}$ dating of early medieval antiquities, accounting for all the factors affecting age, using calibration curves and other dating methods, will help solve the chronological problems of northwestern Russia. 
TABLE 3. ${ }^{14} \mathrm{C}$ Ages of Archaeological Sites of Northwestern Russia

\begin{tabular}{|c|c|c|c|c|c|}
\hline $\begin{array}{l}\text { Sample } \\
\text { no. }\end{array}$ & Sample location & $\begin{array}{l}\text { Sample } \\
\text { material }\end{array}$ & $\begin{array}{l}{ }^{14} \mathrm{C} \text { age } \\
(\mathrm{AD})\end{array}$ & $\begin{array}{l}\text { Cal } A D \text { ages } \\
\text { Stuiver and } \\
\text { Pearson }(1986)^{*}\end{array}$ & $\begin{array}{l}\text { Cal AD ages Stuiver and } \\
\text { Becker }(1986)^{*}\end{array}$ \\
\hline \multicolumn{6}{|c|}{ Vasilyevskoye I } \\
\hline LE-4157 & Hearth wall & Charcoal & $860 \pm 30$ & 911 (949) 987 & $900(915,965) 980$ \\
\hline LE-4388 & Sq. 31,46 & Charcoal & $890 \pm 40$ & $960(987) 1013$ & $904(911,988,1015) 1016$ \\
\hline LE-4389 & Sq. $41,42,51,52$ & Charcoal & $890 \pm 40$ & $960(987) 1013$ & $904(911,988,1015) 1016$ \\
\hline LE-4390 & Sq. 51,54 , upper section & Charcoal & $860 \pm 40$ & $894(944) 993$ & $900(908,970) 995$ \\
\hline LE-4391 & Sq. 51,54 , lower section & Charcoal & $860 \pm 35$ & 900 (948) 995 & $900(906,970) 990$ \\
\hline LE-4392 & Sq. 55 & Charcoal & $860 \pm 25$ & $902(944) 985$ & $910(915,970) 990$ \\
\hline LE-3327 & Sq. 55 & Charcoal & $870 \pm 40$ & 897 (949) 1000 & $897(909,968) 996$ \\
\hline LE-3328 & Sq. 63 & Charcoal & $900 \pm 30$ & $973(993) 1012$ & 985 (993) 1000 \\
\hline \multicolumn{6}{|c|}{ Zemlyanoye Hillfort, Staraya Ladoga } \\
\hline LE-4416 & Layer 3 walkway, Sq. D30 & Wood & $865 \pm 40$ & $895(946) 996$ & $900(913,973) 1000$ \\
\hline LE-4417 & Layer 2 walkway, Sq. E28-D28 & Wood & $940 \pm 40$ & $991(1010) 1028$ & $990(1010) 1030$ \\
\hline LE-4418 & Layer 1 walkway, Sq. E28-D28 & Wood & $940 \pm 40$ & $991(1010) 1028$ & $990(1010) 1030$ \\
\hline LE-4419 & Felling framing, Sq. 330 & Wood & $930 \pm 35$ & $987(1005) 1023$ & $990(1008) 1025$ \\
\hline \multicolumn{6}{|c|}{ Site Near Kotorsk } \\
\hline LE-3215 & $\begin{array}{l}\text { Construction in the pre-original } \\
\text { ground layer }\end{array}$ & Charcoal & $820 \pm 30$ & 890 (928) 965 & $890(935) 980$ \\
\hline \multicolumn{6}{|c|}{ Skovorodka Cemetery, Sopka 2 Mound } \\
\hline LE-3216 & Burial at the top of "Sopka" & $\begin{array}{l}\text { Oak, } \\
\text { charcoal }\end{array}$ & $910 \pm 30$ & 979 (998) 1016 & $980(1000) 1020$ \\
\hline LE-3217 & Burial at the top of "Sopka" & Birch bark & $920 \pm 30$ & $986(1003) 1020$ & $985(995,1013) 1020$ \\
\hline \multicolumn{6}{|c|}{ Storozhinets Hillfort } \\
\hline LE-2810 & Sq. U., 19-419 & Charcoal & $465 \pm 40$ & $545(582) 619$ & $545(578,635) 640$ \\
\hline LE- 4134a & Upper layer of defensive work & Charcoal & $440 \pm 25$ & $531(551) 572$ & $540(563) 585$ \\
\hline LE-4135 & Upper layer of defensive work & Charcoal & $435 \pm 30$ & $508(547) 586$ & $545(563) 580$ \\
\hline \multicolumn{6}{|c|}{ Beryozno Cemetery, long mound $N 18$} \\
\hline LE-4397 & Burial 2 & Charcoal & $470 \pm 25$ & $555(582)(610)$ & $545(575,634) 640$ \\
\hline LE-4399 & Burial 1 & Charcoal & $470 \pm 20$ & $558(582) 606$ & $545(574,634) 635$ \\
\hline \multicolumn{6}{|l|}{ Zaozerye } \\
\hline LE-4400 & Building foundation & Charcoal & $500 \pm 40$ & $577(610) 643$ & $600(601) 645$ \\
\hline LE-4401 & Remains of iron production & Charcoal & $940 \pm 25$ & 1002 (1010) 1018 & $995(1010) 1025$ \\
\hline \multicolumn{6}{|c|}{ Ryurikovo Hillfort, Northern Complex } \\
\hline LE-4405 & $\begin{array}{l}\text { Sq. } 165 \text {, lower section, wood log } \\
\text { from step }\end{array}$ & Wood & $1210 \pm 40$ & 1259 (1269) 1279 & 1260 (1270) 1280 \\
\hline LE-4406 & $\begin{array}{l}\text { Sq. } 165 \text {, lower section, crude } \\
\text { boards }\end{array}$ & Charcoal & $1420 \pm 30$ & $1384(1404) 1424$ & $1330(1335,1415) 1420$ \\
\hline LE-4407 & Sq. 164-171, bottom & Wood & $1485 \pm 20$ & $1428(1435) 1442$ & $1430(1435) 1440$ \\
\hline LE-4408 & Posthole in NW corner & Charcoal & $1600 \pm 75$ & 1448 (1545) 1643 & 1445 (1548) 1650 \\
\hline \multicolumn{6}{|c|}{ Ryurikovo Hillfort, Southern Complex } \\
\hline LE-4411 & Sq. $179, \log$ at base & Wood & $1180 \pm 50$ & $1228(1251) 1275$ & $1220(1250) 1280$ \\
\hline LE-4412 & Charcoal streak at base & Charcoal & $1510 \pm 40$ & $1430(1446) 1462$ & $1425(1440) 1455$ \\
\hline LE-4413 & Sq. 175 , black layer at base & Charcoal & $1520 \pm 25$ & $1437(1448) 1459$ & 1435 (1443) 1450 \\
\hline LE-4414 & Sq. 175,182 , at base & Charcoal & $1500 \pm 30$ & $1430(1444) 1458$ & 1430 (1438) 1445 \\
\hline LE-4415 & Sq. 175,182 , at base & Bones & $1635 \pm 35$ & $1499(1560) 1622$ & $1495(1570) 1645$ \\
\hline \multicolumn{6}{|c|}{ Ryurikovo Hillfort, Moat (end of the 1st millennium $A D$ ) } \\
\hline LE-4404 & Sq. 184 , streaks on walls of moat & Charcoal & $790 \pm 20$ & $875(884) 892$ & $780(785,822,878,931) 940$ \\
\hline
\end{tabular}

*Laboratory error multipliers were not available for these calibrations. 


\section{REFERENCES}

Arslanov, Kh. A. 1978 On corrections to radiocarbondetermined age. Geokhimiya 8: 1157-1164.

1987 Radiocarbon: Geochemistry and Geochronology. $298 \mathrm{pp}$.

Bassalygo, L. A., Sorokin, A. N. and Khoroshev, A. S. 1988 Excavations of the streets of Troitsky: Topography, stratigraphy, chronology. In Novgorod and the Novgorod Region: History and Archaeology, Reports. Novgorod: 63-66.

Bitvinskas, T. T., Dergachyov, V. A., Daukantas, A., Liiva, A. A., Suurma, S. and Shuliya, K. 1978 Using the Radiocarbon Dating Method to Construct Longterm Dendroscales: The Natural Conditions and Radial Growth of Trees. Kaunas: 51-52.

Chernykh, N. B. 1985a Dendrochronology of Ladoga: Excavations of Varyazhskaya Street. In Medieval Ladoga: New Archaeological Discoveries and Research. Leningrad: $120 \mathrm{p}$.

1985b Dendrochronology of the oldest horizons of Ladoga, based on finds from the excavations of the ancient town of Zemlyanoye. In Medieval Ladoga: New Archaeological Discoveries and Research. Leningrad: 78-79.

1987 Dendrochronology of Eastern Europe for the 1st-2nd Millennium AD. Manifestations of Temporal and Spatial Climate Variations in Tree Rings. Part 3. Kaunas: 94 p.

Dergachyov, V. A. 1983 Calibration curves and possibilities for extending time scales. In Proceedings of the 13th Leningrad Seminar on Cosmophysics: The Intensity of Cosmic Ray and Cosmogenic Isotopes. Leningrad: 154-170.

Kolchin, B. A., Bitvinskas, T. T., Chernykh, N. B. and Karpavichyus, I. A. 1984 Wood Samples from Old Novgorod for Radiocarbon Research: Dendrochronology of the Soviet Union, Part 3. Kaunas: 23-25.

Konetskii, V. Ya. 1987 Report of Novgorod Museum expeditions during 1987. Arkhiv IA AN SSSR.

Kocharov, G. E., Bitvinskas, T. T., Vasil'ev, V. A., Dergachyov, V. A., Konstantinov, A. P. Mertskhvarishvili, R. Ya., Ostryakov, V. M. and Stupneva, A. V. 1985 Cosmogenic Isotopes and Astrophysical Phenomena: Astrophysical Phenomena and Radiocarbon. Leningrad: 82-109, 121-131.
Kuz'min, S. L. 1988 The barrows near Beryozno village: The Long Barrows culture in the Plyussy drainage basin. In Archaeology and History of Pskov and the Pskov Region, Reports. Pskov: 81-82.

Markov, Yu. N., Marsadolov, L. S. and Mertskhvarishvili, R. Ya., 1987 A Complex Method of Absolute Dating: Temporal and Space Variations in Climate and Annual Tree Rings, Part 3. Kaunas: 56-73.

Marsadolov, L. S. (ms.) 1985 The Chronology of the Altay Barrows, 8 th- 4 th Centuries BP. Ph.D. dissertation, Leningrad: $16 \mathrm{p}$.

Nosov, E. N. 1984 Novgorod and the Novgorod district, 9th-10th centuries $\mathrm{AD}$, according to the latest archaeological data: On the origin of Novgorod. Novgorod Historical Collection 2(12): 21-23.

1987 Report on the Novgorod regional expedition LOIA AN SSSR for 1987. Arkhiv IA AN SSSR.

1990 Novgorod Ryurikov Ancient Town Site. In press.

Popov, S. G. 1985 Report of the Gdov party LOIA AN SSSR for 1985. Archiv IA Academy of Sciences, USSR.

1988 Research on the ancient town site of Storozhinets. In Archaeology and History of Pskov and the Pskov Region, Reports. Pskov: 61-63.

1989a Storozhinets ancient town site. KSIA 198 45-56.

$1989 \mathrm{~b}$ Radiocarbon dating of northwestern archaeological sites of the second half of the first millennium AD. In Archaeology and History of Pskov and the Pskov Region, Reports. Pskov. In press.

Schmidt, B. and Gruhle, W. 1988 Klima, Radiokohlenstöffgehalt und Dendrochronologie. Naturwissenschaftliche Rundschau. 41(5): 177-182.

Stuiver, M. and Becker, B. 1986 High-Precision decadal calibration of the radiocarbon time scale, AD 19502500 BC. In Stuiver, M. and Kra, R. S., eds., Proceedings of the 12 th International ${ }^{14} \mathrm{C}$ Conference. Radiocarbon 28(2B): 863-910.

Stuiver, M. and Pearson, G. W. 1986 High-Precision calibration of the radiocarbon time scale, AD 1950500 BC. In Stuiver, M. and Kra, R. S., eds., Proceedings of the 12 th International ${ }^{14} \mathrm{C}$ Conference. Radiocarbon 28(2B): 805-838. 